\title{
TITLE: CHEMICAL BONDING OF HYDROGEN MOLECULES OF TRANSITION METAL COMPLEXES
}

AUTHOR(S): $\quad$ Gregory J. Kubas

\section{DISCLAIMER}

This report was prepared as an account of work sponsored by an agency of the United States Government. Neither the United States Government nor any agency thereof, nor any of their employees, makes any warranty, express or implied, or assumes any legal liability or responsibility for the accuracy, completeness, or usefulness of any information, apparatus, product, or process disclosed, or represents that its use would not infringe privately owned rights. Reference herein to any specific commercial product, process, or service by trade name, trademark, manufacturer, or otherwise does not necessarily constitute or imply its endorsement, recommendation, or favoring by the United States Government or any agency thereof. The views and opinions of authors expressed herein do not necessarily state or reflect those of the United States Government or any agency thereof.

\section{SUBMITTED TO: $\quad$ Proceedings of "International Symposium on Metal-Hydrogen Systems" Banff, Alberta, CANADA \\ September 2-7, 1990}

By acceptance of this anticle, the publisher recognizes that the U.S. Government retains a nonexclusive, royalty-free license to publish or reproduce the published form of this contribution, or to allow others to do so, for U.S.Government purposes. 


\title{
CHEMICAL BONDING OF HYDROGEN MOLECULES TO TRANSITION METAL COMPLEXES
}

\author{
Gregory J. Kubas \\ Los Alamos National Laboratory \\ Los Alamos, NM, 87545 (U.S.A.)
}

\section{Introduction}

Until recently the chemistry of hydrogen in metal systems had been universally accepted to involve only its atomic form. However, our unexpected discovery of stable bonding of neutral dihydrogen $\left(\mathrm{H}_{2}\right)$ molecules to molybdenum and tungsten complexes in 1983 has led to a new field of inorganic chemistry and has altered the way chemists now perceive bonding and reactions on metal coordination compounds $[1,2]$. The discovery has been universally characterized to be one of the most significant of the past decade in inorganic chemistry. The $\mathrm{H}-\mathrm{H}$ bond in the neutron diffraction structure of $\mathrm{W}(\mathrm{CO})_{3}\left(\mathrm{PR}_{3}\right)_{2}\left(\mathrm{H}_{2}\right)\left(\mathrm{CO}=\right.$ carbonyl; $\mathrm{PR}_{3}=$ organophosphine) is aligned side-on to the metal $(\mathrm{W}-\mathrm{H}=1.89 \AA)$ and is elongated from $0.74 \AA$ in elemental $\mathrm{H}_{2}$ to $0.82 \AA$ (Fig. 1). Such $\mathrm{M}-\mathrm{H}_{2}$ species had been thought to be only transients in $\mathrm{H}-$ $\mathrm{H}$ bond cleavage to metal hydrides. We have shown that this molecular tungsten complex is a stable crystalline solid under ambient conditions, but the $\mathrm{H}_{2}$ can be reversibly rernoved in vacuum or under inert atmosphere (e. g. argon) even at $25^{\circ} \mathrm{C}$ to give the coordinatively unsaturated precursor, $W(C O)_{3}\left(P R_{3}\right)_{2}$. The dissociation pressure of $\mathrm{H}_{2}$ is 1-10 torr depending on the phosphine $R$ group and the binding energy of $\mathrm{H}_{2}$ to the complex is about $15 \mathrm{kcal} / \mathrm{mol}$. The $\mathrm{H}_{2}$ is thus weakly bound, easily exchanges with $D_{2}$, and can be readily displaced by other more strongly held molecules such as $\mathrm{CO}$ or even $\mathrm{N}_{2}$ (the complex is decomposed by atmospheric oxygen). Complete isotopic scrambling of $\mathrm{H}_{2} / \mathrm{D}_{2}$ mixtures to give $H D$ occurs over the solid complex or in solution (the complexes are soluble in organic solvents, such as toluene, but not water). Surprisingly, the 6-coordinate $\mathrm{H}_{2}$ complex can exist in dynamic equilibrium with its 7-coordinate dihydride form in the solution phase, indicating little energy difference between these rapidly interconverting species.

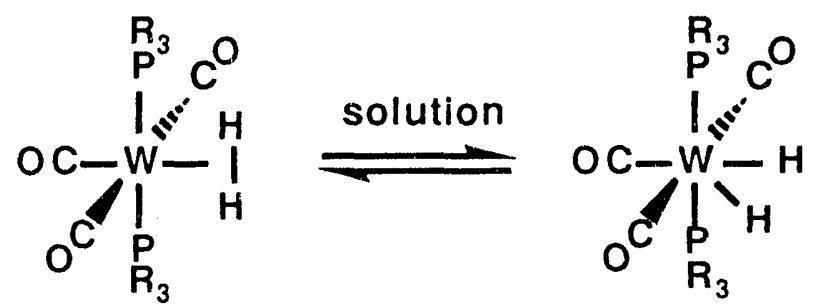


The ratio of $\mathrm{H}_{2}$ complex to dihydride is about 4:1 and thermodynamic measurements [3] show $\Delta H^{\circ}$ to be only $1.5 \mathrm{kcal} / \mathrm{mol}$ and $\Delta H^{\prime} \neq=10 \mathrm{kcal} / \mathrm{mol}$. The dihydride has not been isolated or observed in the solid state but was readily observed in solution by infrared and NMR spectroscopy.

Many new examples of $\mathrm{H}_{2}$ complexes have now been found throughout the transition metal series and even the actinides ( 60 complexes) [2], and nearly 200 papers have been published on the subject. Included are several polyhydride complexes that had long been believed to contain only classical hydrides, e. $g$. $\mathrm{FeH}_{4}\left(\mathrm{PR}_{3}\right)_{3}$, which has recently been shown by neutron diffraction [4] to be actually $\mathrm{FeH}_{2}\left(\mathrm{H}_{2}\right)\left(\mathrm{PR}_{3}\right)_{3}$ (Fig. 2). By far the most common electronic structure of dihydrogen complexes is $d^{6}$ (metals in oxidation states containing 6 d-electrons, e. $g . W(0)$ ) with overall octahedral coordination of ligands around the metal center. Ionic dihydrogen complexes can be formed by protonation of hydride complexes in solution with both strong (e. g. $\mathrm{HBF}_{4}$ ) and weak (e. g. alcohols) asids: $\mathrm{M}-\mathrm{H}+\mathrm{H}^{+}[\text {anion }]^{-} \rightarrow[\mathrm{M}-$ $\left.\mathrm{H}_{2}\right]^{+}$[anion]- where $\mathrm{M}$ represents a meial-ligand fragment such as $\mathrm{Fe}(\mathrm{H})\left(\mathrm{PR}_{3}\right)_{4}$. The bound $\mathrm{H}_{2}$ here can be very acidic, readily transfering a proton to a base and displaying aqueous $p K_{a}$ values ranging from -2 (i. e. as strong as sulfuric acid!) to 18 [5]. Metal-bound $\mathrm{H}_{2}$ was found to transfer hydrogen (as $\mathrm{H}^{+}$) to bases more readily than hydride ligands coexisting on the same metal center.

$\mathrm{H}_{2}$ has also been found to molecularly bind to metal surfaces such as $\mathrm{Ni}(510)$ [6], palladium atoms in rare-gas matrices [7], and small metal atom clusters (e. g. $\mathrm{Cu}_{2}\left(\mathrm{H}_{2}\right)_{2}, \mathrm{Cu}_{2}\left(\mathrm{H}_{2}\right)_{3}, \mathrm{Cu}_{3}\left(\mathrm{H}_{2}\right), \mathrm{Fe}_{\mathrm{x}}\left(\mathrm{H}_{2}\right)(\mathrm{x}=3$ or 4$)$ at low temperatures [8]. The relevance of $\mathrm{M}-\mathrm{H}_{2}$ binding to catalytic hydrogenation mechanisms and hydrogen storage is readily apparent. Even the function of metal-containing biological enzymes such as nickel hydrogenases are now being considered in terms of molecular hydrogen binding [9].

\section{Bonding and Cleavage of the $\mathrm{H}-\mathrm{H}$ Bond}

Importantly, the tungsten complex represented the first stable compound containing intermolecular interaction of a sigma-bond $(\mathrm{H}-\mathrm{H})$ with a metal and serves as a prototype for other "nonclassical" (2-electron, 3-center) complexes (e. g. the bonding of $\mathrm{C}-\mathrm{H}$ bonds to metals). Searches are now on for stable methane or other alkane binding to metals (observable only at low temperature). Extensive theoretical investigations of metal-dihydrogen bonding have been carried out using primarily ab initio and Extended Huckel calculational techniques [2,10]. The bonding model is 
similar to that of the Dewar-Chatt-Duncanson model of metal-olefin bonding (Fig. 3). The primary interaction is donation of electron density from the $\mathrm{H}_{2}$ bonding electron pair ( $\sigma$-orbital) to a vacant metal d-orbital. There is also, to a lesser degree, "backdonation" into the $\sigma^{*}$ antibonding orbital of $\mathrm{H}_{2}$ from a filled d-orbital, which is of major importance. It is responsible for the side-on bonding of $\mathrm{H}-\mathrm{H}$ to metals and also represents the mechanism by which $\mathrm{H}_{2}$ is cleaved to atomic hydride. Clearly if the amount of backdonation becomes excessive (e. g. increasing the energy of the metal d-orbital by increasing electron density on the metal), the $\mathrm{H}-\mathrm{H}$ bond is ruptured because of overpopulation of the antibonding $\mathrm{H}_{2}$ orbital. The formation of a dihydride from the tungsten $-\mathrm{H}_{2}$ complex discussed above graphically demonstrates this cleavage process. In addition we have shown that one can "fine tune" $\mathrm{H}_{2}$ interaction with metal complexes to bind either as dihydrogen or dihydride by adjusting the electron-donating properties of the co-ligands (e. g. phosphines). To effect this we synthesized a series of complexes of molybdenum of the type $\mathrm{MC}(\mathrm{CO})\left(\mathrm{H}_{2}\right)\left(\mathrm{R}_{2} \mathrm{PCH}_{2} \mathrm{CH}_{2} \mathrm{PR}_{2}\right)_{2}$ and varied the organo phosphine substituent, $\mathrm{R}$. For $R=$ phenyl (a poorer electron donor), the complex contains molecularly bound hydrogen in the typical 6-coordinate octahedral structure (Fig. 4), but for the more inductively electron-donating substituents $R=$ ethyl or isobutyl, the complex now exists as a 7-coordinate dihydride with a completely rearranged structure (pentagonal bipyramid, Fig 4) [11]. All that has been changed is the net "electron-richness" of the molybdenum, which increases the amount of $\mathrm{Mo} \rightarrow \sigma^{*} \mathrm{H}_{2}$ backdonation, resulting in breakage of the $\mathrm{H}-\mathrm{H}$ bond. The same effect has been demonstrated by changing the metal from Mo to more electron-rich $W$.

The $\mathrm{H}-\mathrm{H}$ bond length should be a measure of the degree of weakening of the $\mathrm{H}-$ $\mathrm{H}$ bond. So far three neutron diffraction structures of $\mathrm{H}_{2}$ complexes have been carried out $[1,4,12]$ and they all show distances of $0.82 . \AA(\sim 0.79 \AA$ for a preliminary refinement of the neutron structure of the above Mo complex). This is probably fortuitous because there is increasing evidence for elongated distances near or even greater than $1.0 \AA$. An $x$-ray structure [13] of a rhenium complex with three classical hydrides and a dihydrogen ligand showed an $\mathrm{H}-\mathrm{H}$ distance of $1.06 \dot{A}$, although $x$-ray determined distances are not reliable and must be confirmed by neutron diffraction. Solid state ${ }^{1} \mathrm{H}$ NMR experiments by Zilm at Yale [14] also indicate distances near $1.0 \AA$ for ruthenium $-\mathrm{H}_{2}$ complexes. These same experiments showed $\mathrm{H}-\mathrm{H}$ to be $0.89 \AA$ in our tungsten complex, a distance $0.07 \AA$ longer than in the neutron structure. This discrepancy may be rationalized by the fact that the bound $\mathrm{H}_{2}$ undergoes rapid rotation or at the least librational motion about the metal- $\mathrm{H}_{2}$ axis even at low 3 
temperatures (see below). The thermal motion may result in an effective shortening of the actual $\mathrm{H}-\mathrm{H}$ distance as observed by neutron diffraction. The determination of the real $\mathrm{H}-\mathrm{H}$ internuclear distance is thus not straightforward, and the question of how long can an $\mathrm{H}-\mathrm{H}$ bond be before it no longer can be considered a bond will be the subject of much speculation and experiment in the near future.

Infrared and NMR Spectroscopic Studies

The infrared spectrum of our tungsten-dihydrogen complex displayed the six vibrational modes that we calculated to exist for a bound $\mathrm{H}_{2}$ (only two exist for a hydride, $v(\mathrm{M}-\mathrm{H})$ and $\delta(\mathrm{M}-\mathrm{H})$ ) [1]. The $\mathrm{H}-\mathrm{H}$ stretch was located as a very broad, weak bano near $2700 \mathrm{~cm}^{-1}$ for a solid sample. Symmetric and asymmetric $\mathrm{W}-\mathrm{H}_{2}$ modes were located at 1570 and $950 \mathrm{~cm}^{-1}$, and two deformational modes $\left(\sim 650\right.$ and $450 \mathrm{~cm}^{-}$ 1) were also located, all of which shifted as expected on dueterium substitution (for both the $\mathrm{HD}$ and $\mathrm{D}_{2}$ isotopomers). Inelastic neutron scattering located the torsional (rotational) mode at $\sim 350 \mathrm{~cm}^{-1}$. Thus far our complexes are the only ones in which all of these modes have been observed, but the $\mathrm{H}-\mathrm{H}$ stretch has been observed in several unstable species at low temperature [2]. It has been found to vary in the range $3100-2200 \mathrm{~cm}^{-1}$, much lower than that in free $\mathrm{H}_{2}\left(4300 \mathrm{~cm}^{-1}\right)$. Several vibrational modes similar to those for our complexes have been seen for the $\mathrm{Ni}(510)-\mathrm{H}_{2}$ interaction by EELS spectroscopy [6] and also for $\mathrm{Pd}-\mathrm{H}_{2}$ [7].

Solution ${ }^{1} \mathrm{H}$ NMR spectra of dihydrogen complexes typically show a broad single resonance due to the $H_{2}$. HD complexes give a diagnostic 1:1:1 triplet pattern due to $\mathrm{HD}$ coupling $(I D=1)$, which varies from $10-36 \mathrm{~Hz}(J(H D)=43 \mathrm{~Hz}$ for $\mathrm{HD}$ gas). Crabtree demonstrated that the $\mathrm{H}_{2}$ ligand has a very short relaxation time $\mathrm{T}_{1}$ on the order of 4$40 \mathrm{~ms}$, thus giving another aid to determining whether dihydrogen binding is present in a complex [2]. The main reason for the low $T_{1}$ is dipolar $\mathrm{H}-\mathrm{H}$ coupling which varies as $r^{6}$ and thus is strongly influenced by the short $\mathrm{H}-\mathrm{H}$ distance for bound $\mathrm{H}_{2} . \mathrm{H}-\mathrm{H}$ bond distances have been estimated by solution NMR and also indicate elongated distances near or greater than $1.0 \AA$ in several complexes [15].

Dynamics, Rotation, and Quantum Mechanical Phenomena of Bound $\mathrm{H}_{2}$

Metal dihydrogen/hydride systems exhibit a remarkable variety of dynamic behavior: the bound $\mathrm{H}_{2}$ ligand undergnes (1) reversible dissociation from the metal, (2) rapid propeller-like rotation about the $\mathrm{M}-\mathrm{H}_{2}$ axis, (3) isotopic scrambling, (4) intramolecular exchange with hydride co-ligands, and (5) cleavage to two hydride 
ligands, all of which can occur simultaneously and as equilibrium processes. The energy barrier to rotation of bound $\mathrm{H}_{2}$ has been studied experimentally and theoretically in relation to the bonding model for $M-H_{2}$. As discussed above, metal $\longrightarrow \mathrm{H}_{2} \sigma^{*}$ "backbonding" is crucial to the stability of $\mathrm{H}_{2}$ complexes, and the extent of this bonding should be reflected by the magnitude of the rotational barrier. This is due to the anisotropy that exists in the co-ligand arrangement and therefore in metal $d$ orbital energies. The $\mathrm{H}-\mathrm{H}$ bond axis can align parallel to either the phosphine-Wphosphine vector or the OC-W-CO vector in Fig. 1, and the energy difference between these orientations represents the rotational barrier (the $\mathrm{H}_{2} \sigma$ donation to the vacant. metal d-orbital has no orientational preference). Both experimental studies and $a b$ initio calculations show that the $\mathrm{H}-\mathrm{H}$ prefers to align along the P-W-P axis because the d-orbital in this direction is of higher energy (the phosphines are much better electron donors than $\mathrm{CO}$ ), with an energy difference of $1.8 \mathrm{kcal} / \mathrm{mol}$ for $\mathrm{W}(\mathrm{CO})_{3}\left(\mathrm{PR}_{3}\right)_{2}\left(\mathrm{H}_{2}\right) \quad(\mathrm{R}=$ cyclohexyl). Calculations using standard "molecular mechanics" programs also showed that nonbonding repulsive interactions between the $\mathrm{H}_{2}$ and the bulky organophosphines were found not to be significant in hindering $\mathrm{H}_{2}$ rotation. We have been able to experimentally determine the rotational energy barriers by inelastic neutron scattering methods, particularly rotational tunneling spectroscopy which measures the ground state splitting energy of $\mathrm{H}_{2}$ in a standard double-minimum potential well [16]. We have determined that this type of potential is an excellent model for the $\mathrm{H}_{2}$ rotation, with the assumption of rotation with one degree of freedom (possibly the first example of this for $\mathrm{H}_{2}$ as first described by Pauling [17]). The barriers are quile low, ranging from $1-3 \mathrm{kcal} / \mathrm{mol}$, and agreed well with the ab initio calculations. These results show that backbonding does exist and also that inelastic neutron scattering is a good diagnostic for $\mathrm{H}_{2}$ binding. The barrier to rotation in the $\mathrm{Fe}$ complex (Fig. 2) is particularly low, $1.0 \mathrm{kcal} / \mathrm{mol}$, alıd this has been ascribed to a weak interaction between the $\mathrm{H}_{2}$ ligand and a cis hydride $(\mathrm{H}(3))$ wherein there is donation of electron density from the $\mathrm{Fe}-\mathrm{H}(3)$ bonding orbital to the $\sigma^{*}$ orbital of $\mathrm{H}_{2}$ [4]. This "cisinteraction" shown in Fig. 5 competes with the normally preferred orientation of the $\mathrm{H}$ $\mathrm{H}$ bond parallel to the $\mathrm{P}(1)-\mathrm{W}-\mathrm{H}(3)$ axis, resulting in a rather flat potential (low barrier) and also the unusual alignment of the $\mathrm{H}_{2}$ at a $45^{\circ}$ angle to metal-ligand axes. Fig. 5 show that this interaction is the first step towards formation of a transient $\mathrm{H}_{3}$ ligand which has often been proposed to be an intermediate in exchange of $\mathrm{H}_{2}$ and hydride. $\mathrm{H}_{3}+$ is a known mass-spectrometer molecule and its possible stabilization on a metal complex has been proposed [18] but thus far has not been observed. 
The above-mentioned rotational tunneling is a quantum mechanical effect (neutron-induced spin-flip, essentially para $(l=0, J=0)$ to ortho $(l=1, J=1)$ transitions within the ground librational state of the $\mathrm{H}_{2}$ ) observable even in the remarkably high temperature regime of 180-200 K. An unusual solution NMR exchange coupling phenomenon has recently been observed in iridium trihydride complexes, $\left[\mathrm{C}_{5}\left(\mathrm{CH}_{3}\right)_{5}\right] \mathrm{Ir} \mathrm{H}_{3}(\mathrm{~L})$ ( $\mathrm{L}=$ phosphine-type donor), in this temperature range which also has been determined to be a quantum mechanical process [19]. In this system, coherent motion of the three hydrides produces extraordinarily large ${ }^{1} \mathrm{H}-1 \mathrm{H}$ coupling constants (thousands of Hertz!) with huge temperature dependences. These phenomena emphasize that one must always be alert for novel quantum mechanical behavior in hydrogen systems, even at the "low" temperatures (relatively-speaking) at which many experiments are routinely carried out. Lastly, we are also utilizing neutron scattering measurements in the regime of the transition from quantum mechanical to classical behavior (quasi-elastic neutron scattering) to obtain information about dihydrogen/hydride exchange processes.

\section{Conclusion}

The now well-documented existence of molecularly-bound $\mathrm{H}_{2}$ on metal complexes, metal surfaces, and metal atoms obviously gives cause for speculation about the existence of hydrogen pairing in bulk metal hydride systems. We have shown that the molecularly bound state is quite sensitive to several factors: (1) the overall electron "richness" of the metal center and electronic configuration ( $d^{6}$ favored), (2) the presence of strong trans-influence ligands such as $\mathrm{CO}$ opposite the $\mathrm{H}_{2}$ on the metal, which moderates the metal to $\mathrm{H}_{2}$ backbonding, (3) solid versus solution state, and, only to a very small degree, temperature (4) as a corollary to (1), the charge of the metal complex (cation versus neutral), (5) oxidation state of the metal (usually low). In regard to (1), the electronics at the metal in metal complexes are highly controlled by ancillary ligands (electron donors versus acceptors), which of course are not present in bulk hydrides. However, there could exist conditions in the latter systems favoring at least partial or local formation of hydrogen pairing, perhaps at temperatures higher $(>400 \mathrm{~K})$ than those of the normal stability range of organo-metal- $\mathrm{H}_{2}$ complexes. It is becoming more apparent from the now numerous studies of $\mathrm{H}_{2}$ complexes that the possible distances between $\mathrm{H}$ atoms surrounding a metal may exist as a continuum from $0.74 \AA$ to $>1.5 \AA$ rather than as specific ranges corresponding to either bound dihydrogen with $\mathrm{H}-\mathrm{H}=\sim 0.82 \AA$ or hydride $(>1.5 \AA)$. Also, recent evidence has been reported for a Ru-porphyrin system containing $\mathrm{H}_{2}$ chemically bonded between two $\mathrm{Ru}$ 6 
metal centers, possibly the first example of a bridging molecular hydrogen group [20]. Searches have been made for the elusive $\mathrm{H}_{3}$ ligand, and novel quantum mechanical behavior of dihydrogen and hydride systems have been observed. Thus the frontiers of dihydrogen chemistry appear boundless, and new findings worldwide are now making what was initially an extraordinary chemical bonding phenomenon look to be almost commonplace.

\section{Acknowledgements}

Support from the Department of Energy, Basic Energy Sciences, Office of Chemical Sciences, and Los Alamos National Laboratory's Institutional Supporting Research and Development Fund is gratefully acknowledged.

\section{References}

1. G. J. Kubas, R. R. Ryan, B. I. Swanson, P. J. Vergamini, and H. J. Wasserman, J. Am. Chem. Soc. 106, 451 (1984) and G. J. Kubas, C. J Unkefer, B. I. Swanson, and E. Fukushima, J. Am. Chem. Soc. 108, 7000 (1986).

2. G. J. Kubas, Acct. Chem. Res. 21, 120 (1988) and R. H. Crabtree, ibid. 23 , 95 (1990).

3. G. R. K. Khalsa, G. J. Kubas, C. J. Unkefer, L. S. Van Der Sluys, and K. A. KubatMartin, J. Am. Chem. Soc. 112, 3855 (1990).

4. L. S. Van Der Sluys, J. Eckert, O. Eisenstein, J. H. Hall, J. C. Huffman, S. A. Jackson, T. F. Koetzle, G. J. Kubas, P. J. Vergamini, and K. G. Caulton, J. Am. Chem. Soc. 112, 4831 (1990).

5. M. S. Chinn, D. M. Heinekey, N. G. Payne, and C. D. Sofield, Organometallics $\underline{8}$, 1824 (1989) and R. H. Morris, private communication.

6. A.-S. Martensson, C. Nyberg, and S. Andersson, Phys. Rev. Lett. 57, 2045 (1986) and Surface Sci. 205, 12 (1988).

7. G. A. Ozin, and J. Garcia-Prieto, J. Am. Chem. Soc. 108, 3099 (1986).

8. R. H. Hauge, J. L. Margrave, and Z. H. Kafafi, NATO ASI Ser., Ser. B 158 (Phys. Chem. Small Clusters), 787 (1986).

9. R. H. Crabtree, Inorg. Chim. Acta 125, L7 (1986) and S. P. J. Albracht, Rec. Trav. Chim. Pays-Bas 106, 173 (1987).

10. P. J. Hay, J. Am. Chem. Soc. 109, 705 (1987) and A. G. Ginsburg and A. A. Bagaturyants, Metalloorg. Khim. 2, 249 (1989) and references therein.

11. G. J. Kubas, R. R. Ryan, and C. J. Unkefer, J. Am. Chem. Soc. 109, 8113 (1987). 
12. J. S. Ricci, T. F. Koetzle, M. T. Bautista, T. M. Hofstede, R. H. Morris, and J. F. Sawyer, J. Am. Chem. Soc. 111, 8823 (1989).

13. Y. Kim, H. Deng, D. W. Meek, and A. Wojcicki, J. Am. Chem. Soc. 112, 2798 (1990).

14. K. W. Zilm and J. M. Millar, Adv. Magnetic and Optical Resonance 15, 163 (1990) and K. W. Zilm, R. A. Merrill, M. W. Kummer, and G. J. Kubas, J. Am. Chem. Soc. 108, 7837 (1986).

15. D. G. Hamilton, and R. H. Crabtree, J. Am. Chem. Soc. 110, 4126 (1988); M. T. Bautista, K. A. Earl, P. A. Maltby, R. H. Morris, C. T. Schweitzer, and A. Sella, J. Am. Chem. Soc. 110, 7031 (1988); and ref. 2 (Crabtree).

16. J. Eckert, G. J. Kubas, J. H. Hall, P. J. Hay, and C. M. Boyle, J. Am. Chem. Soc. 112,2324 (1990).

17. L. Pauling, Phys. Rev. 36,430 (1930).

18. J. K. Burdett, J. R. Phillips, M. R. Pourian, M. Poliakoff, J. J. Turner, and R. Upmacis, Inorg. Chem. 26, 3054 (1987).

19. K. W. Zilm, D. M. Heinekey, J. M. Millar, N. G. Payne, and P. Demou, J. Am. Chem. Soc. 111, 3088 (1989); D. M. Heinekey, J. M. Millar, T. F. Koetzle, N. G. Payne, and K. W. Zilm, J. Am. Chem. Soc. 112, 909 (1990); and K. W. Zilm, D. M. Heinekey, J. M. Millar, N. G. Payne, S. P. Neshyba, J. C. Duchamp, and J. Szczyrba, J. Am. Chem. Soc. 112, 920 (1990). See also the first citation in Ref. 14.

20. J. P. Collman, J. E. Hutchison, P. S. Wagenknecht, N. S. Lewis, M. A. Lopez, and R. Guilard, J. Am. Chem. Soc. 112, 8206 (1990). 


\section{Eigure Captions}

Figure 1. Neutron diffraction structure of $W(C O)_{3}\left(\mathrm{PR}_{3}\right)_{2}\left(\mathrm{H}_{2}\right)\left(\mathrm{R}=\mid\right.$ sopropyl $\left.=i-\mathrm{C}_{3} \mathrm{H}_{7}\right)$ at $30 \mathrm{~K}$ (the lower phosphine ligand is disordered).

Figure 2. Neutron diffraction structure of $\mathrm{FeH}_{2}\left(\mathrm{H}_{2}\right)\left[\mathrm{P}\left(\mathrm{C}_{6} \mathrm{H}_{5}\right)_{2}\left(\mathrm{C}_{2} \mathrm{H}_{5}\right)\right]_{3}$ at $27 \mathrm{~K}(\mathrm{H}-\mathrm{H}=$ $0.82 \AA)$.

Figure 3. Bonding model for metal- $\mathrm{H}_{2} \sigma$-complex compared to model for metalolefin $\pi$-complex.

Figure 4. Representation of the structures of the reaction products of $\mathrm{H}_{2}$ with the unsaturated precursor $\mathrm{Mo}(\mathrm{CO})\left(\mathrm{R}_{2} \mathrm{PCH}_{2} \mathrm{CH}_{2} \mathrm{PR}_{2}\right)_{2}$ to give either an $\mathrm{H}_{2}$ complex or a dihydride depending solely on the nature of the organo-substituent $\mathrm{R}$ : phanyl (Ph) versus ethyl (Et) or isobutyl ( $i-\mathrm{Bu})$.

Figure 5. Cis-interaction between dihydrogen and hydride, leading to formation of a transient metal-trihydrogen complex, which can freely rotate to give site exchange of hydrogen (labelled with asterisk) from hydride to dihydrogen. 


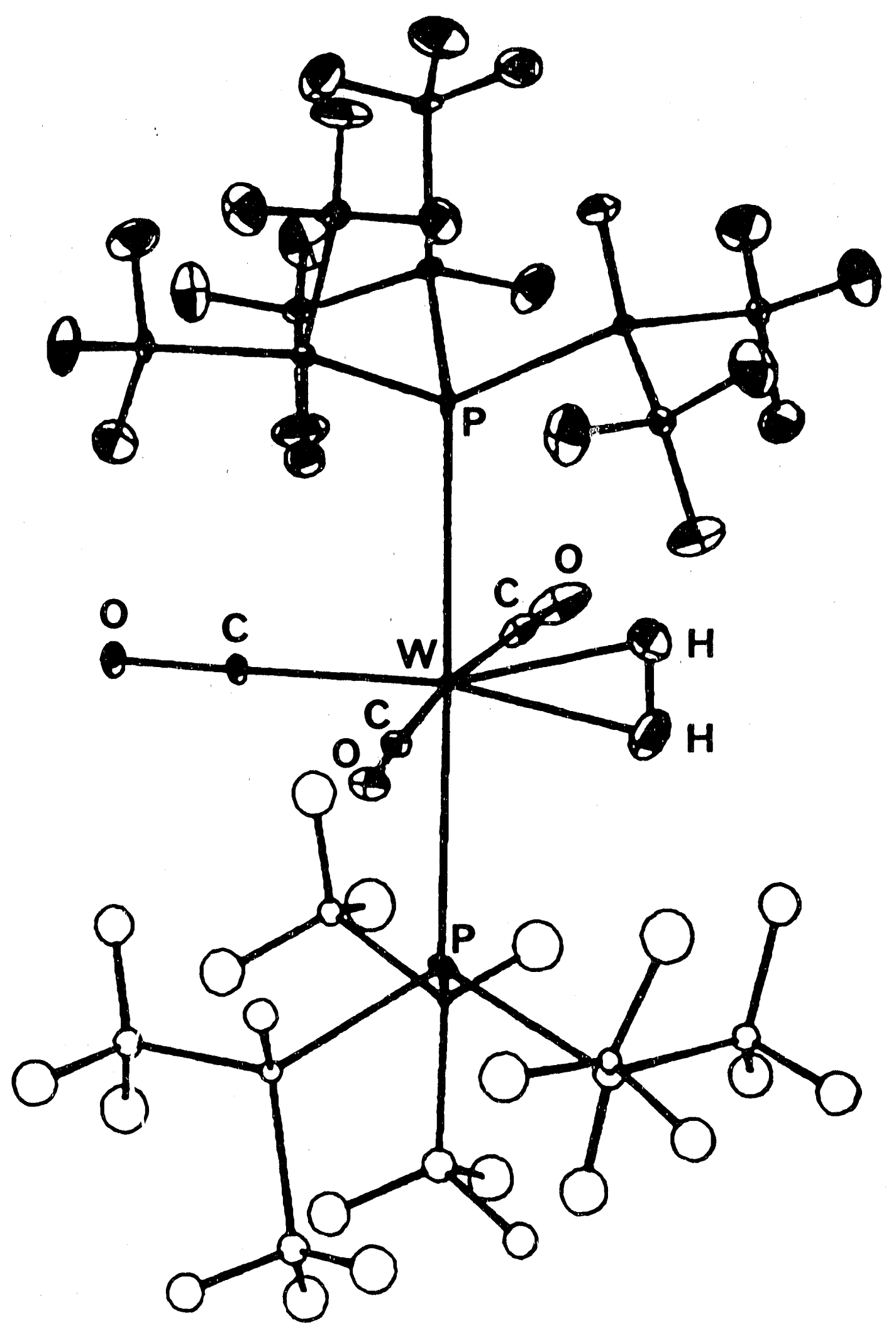




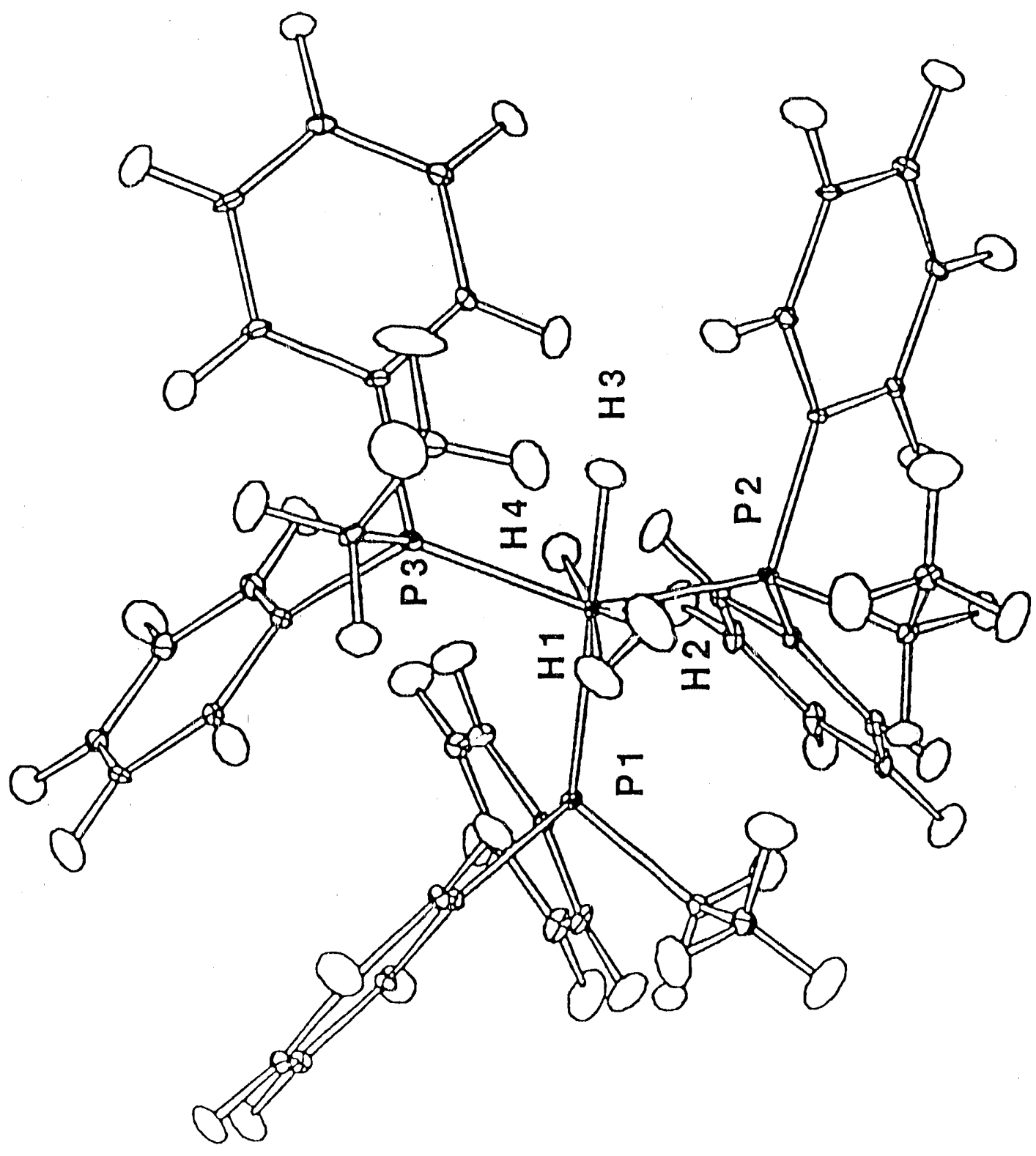



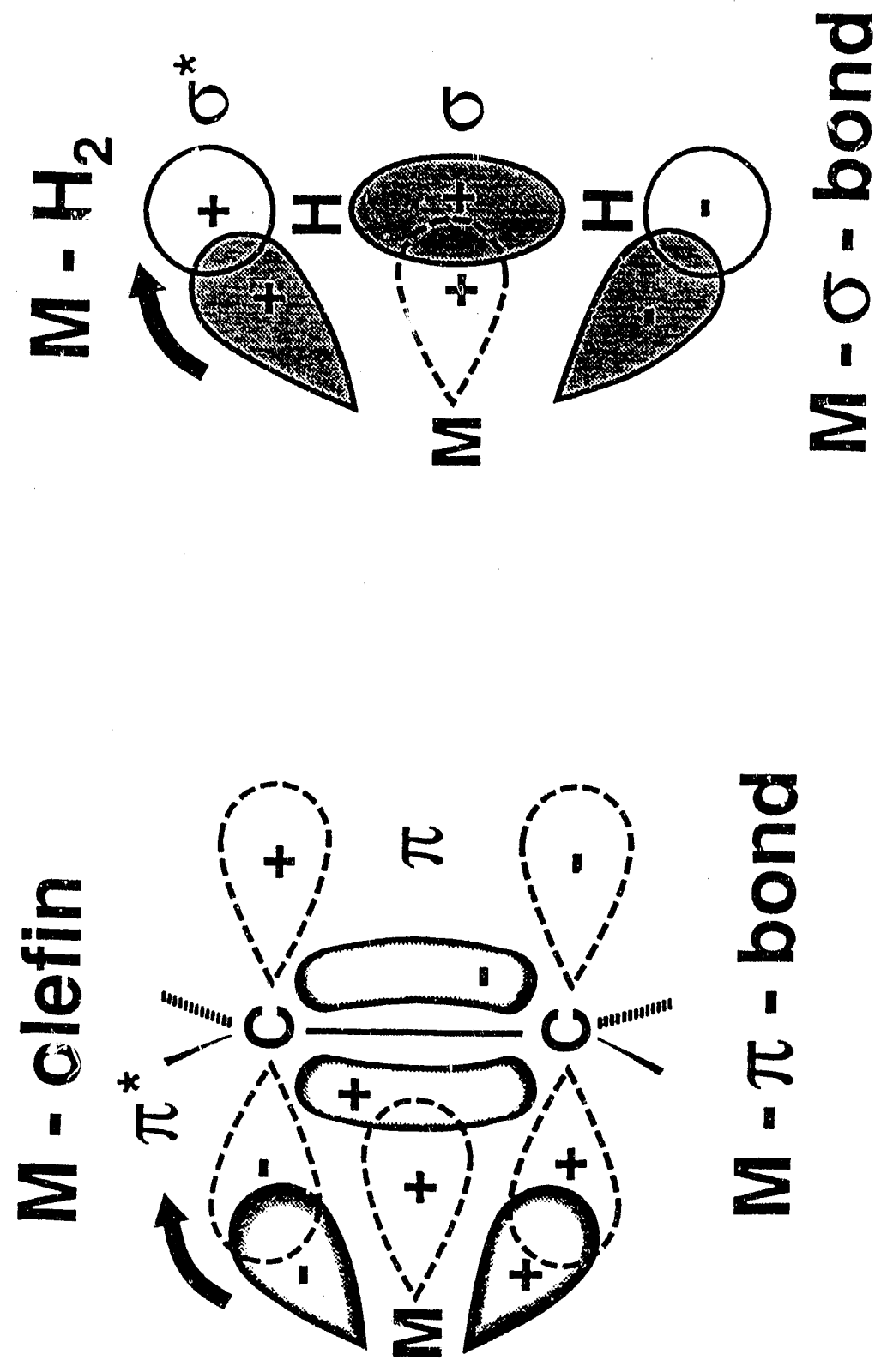


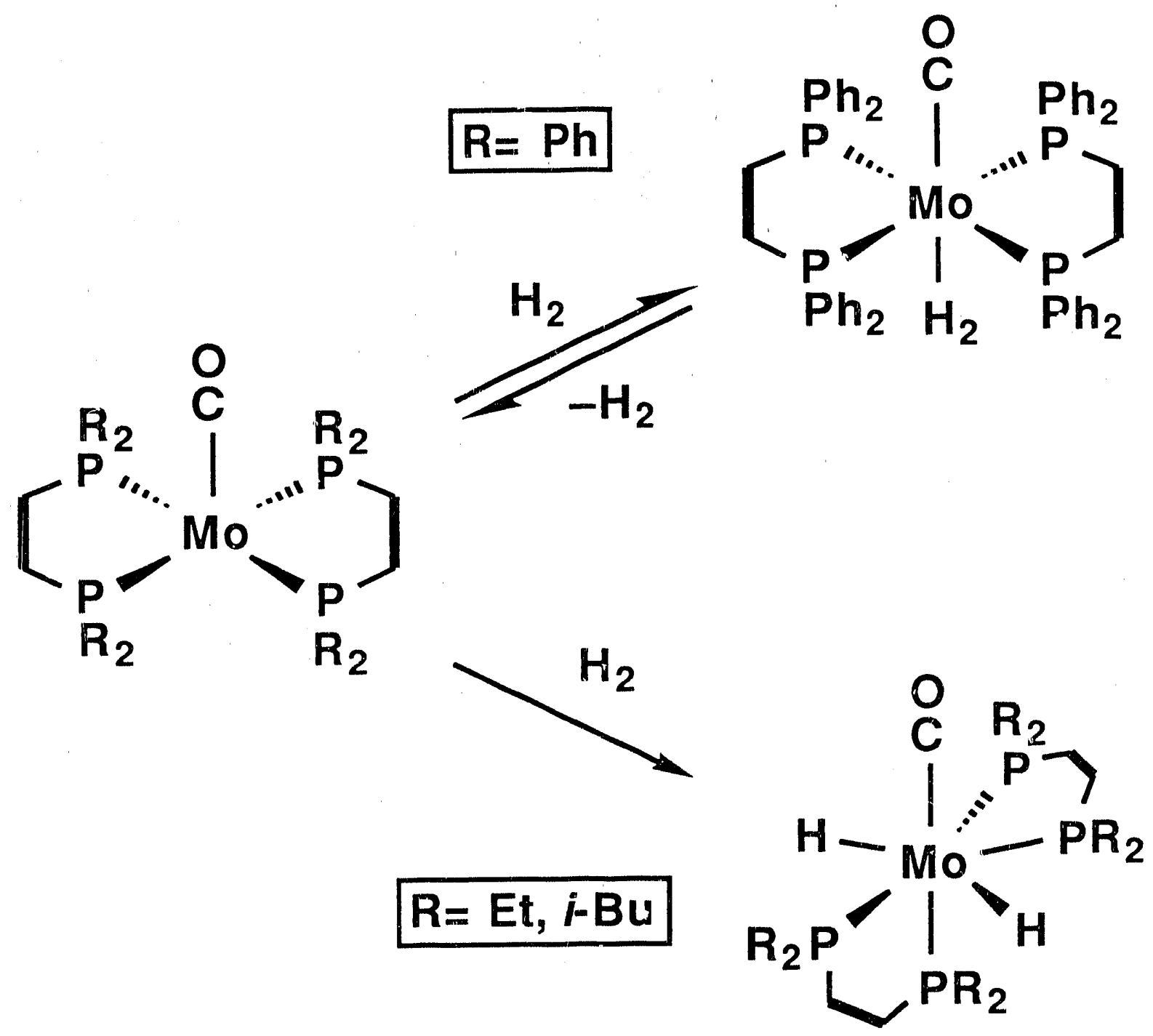



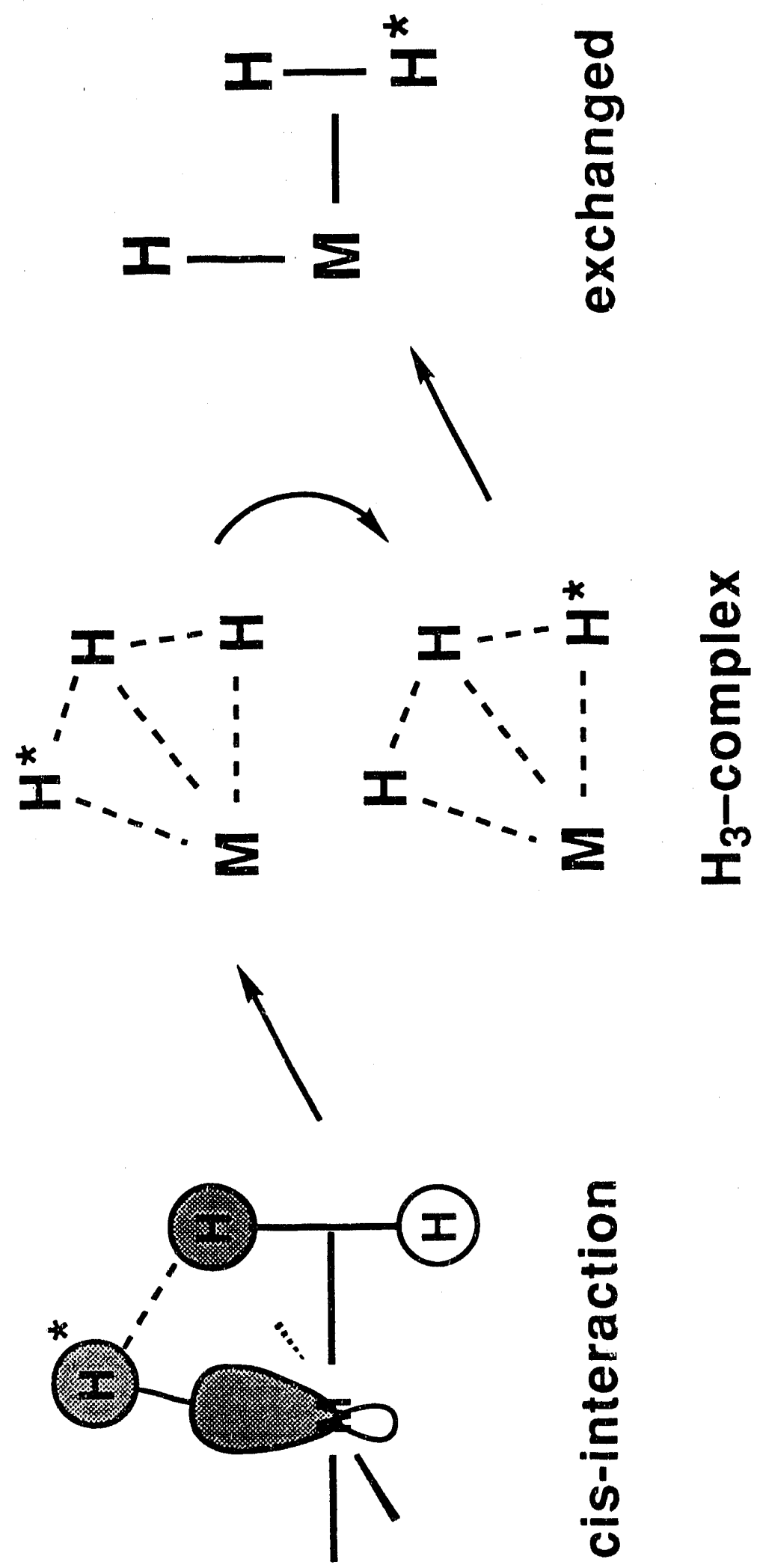

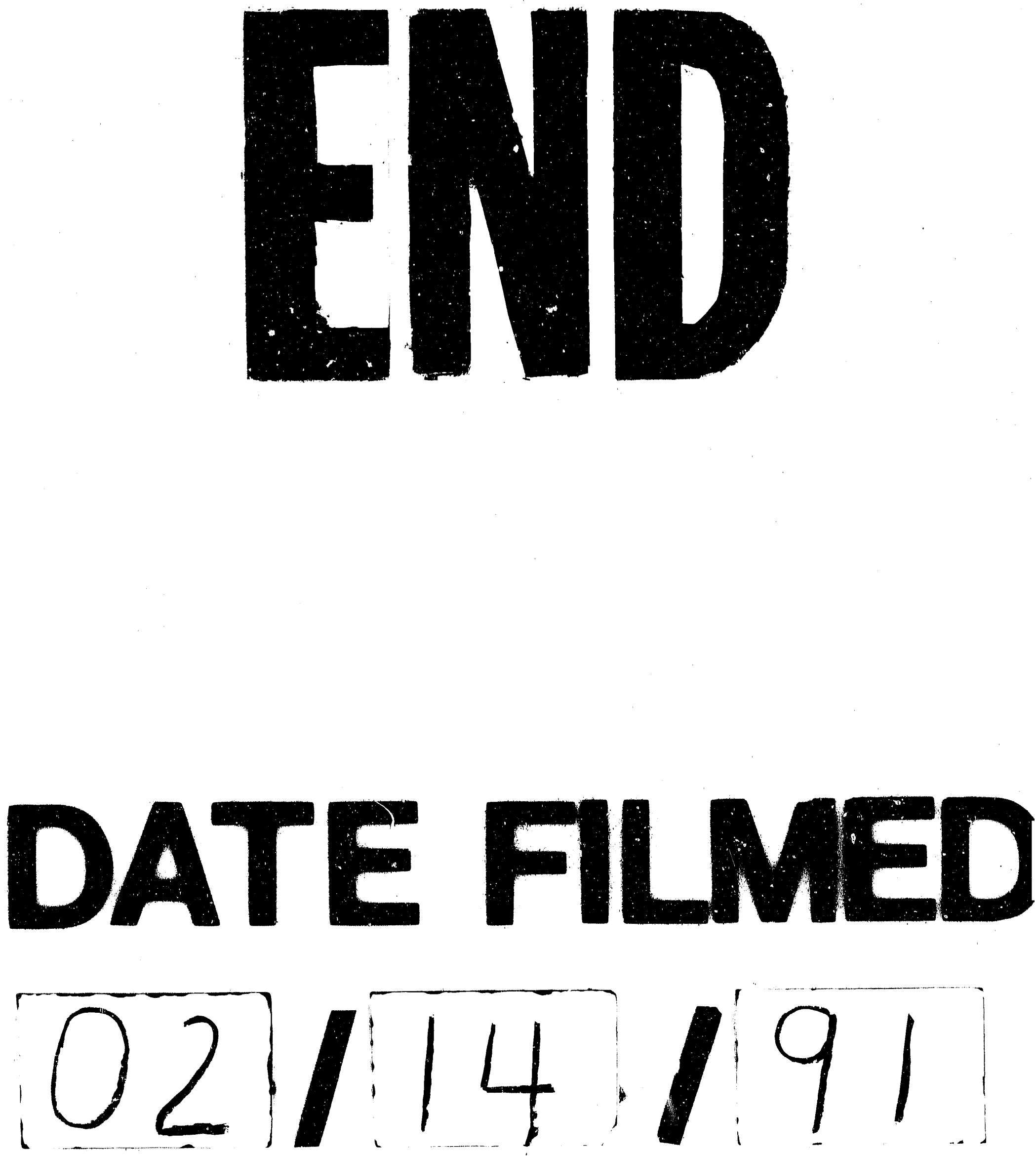
